\title{
Progenesis in Late Eocene populations of Subbotina linaperta (Foraminifera) from the western Atlantic
}

\author{
Norman Macleod ${ }^{1,4}$, Gerta Keller ${ }^{2}$ and Jennifer A. Kitchell ${ }^{3,5}$ \\ 'Department of Geological Sciences and Museum of Paleontology, University of Michigan, Ann Arbor, MI 48109 (U.S.A.) \\ ${ }^{2}$ Department of Geological and Geophysical Sciences, Princeton University, Princeton, NJ 08544 (U.S.A.) \\ ${ }^{3}$ Department of Geological Sciences of Paleontology, University of Michigan, Ann Arbor, MI 48109 (U.S.A.)
}

(Revised manuscript accepted January 10, 1990)

\begin{abstract}
MacLeod, N., Keller, G. and Kitchell, J.A., 1990. Progenesis in Late Eocene populations of Subbotina linaperta (Foraminifera) from the western Atlantic. Mar. Micropaleontol., 16: 219-240.

It has been argued that the successive appearance of a distinct set of test morphologies by planktic foraminifera represents evidence for the multiple evolution of mechanical optima (Steineck and Fleisher, 1978). However, morphometric, isotopic and biostratigraphic analyses of the globigerine species Subbotina linaperta from Middle-Late Eocene Atlantic Ocean deep sea cores suggests that changes in developmental pathways may also play an important role in planktic foraminiferal evolution. During a period of prolonged and global change in the Middle-Late Eocene marine environment, at least one western Atlantic population of $S$. linaperta was characterized by a marked decrease in mean test size that persisted throughout the remainder of this species' teilzone. In addition, this Late Eocene population exhibited anomalous relative abundances and a pronounced change in depth habitat when compared to conspecific populations in the Gulf of Mexico and South Atlantic. Quantitative morphometric analyses indicate the observed size reduction to be a secondary result of selection for the ontogenetically accelerated attainment of sexual maturity; a mode of developmentally mediated evolution termed progenesis. The temporal persistence of this progenetically dwarfed population throughout the remainder of the Late Eocene at this locality serves to illustrate the potential of this evolutionary mechanism to produce sustained morphological and ecological changes within populations of marine plankton as well as implying that this population was at least partially isolated from the general circulation of the Gulf Stream during this time interval. In addition, similarities between the nature of phenotypic change in this population and the common anecdotal observation of test size reduction in a number of planktic foraminiferal lineages at the Cretaceous-Tertiary boundary and during the Paleogene-Neogene faunal transition suggest that selection for different developmental patterns may provide an alternative explanation for the reappearance of simple globigerine morphotypes after major planktic foraminiferal extinction events.
\end{abstract}

\section{Introduction}

There is a growing appreciation of the interplay between developmental and evolutionary processes. Both genetic and environmental perturbations can causally influence within-lineage developmental histories either directly,

${ }^{4}$ Current address: Department of Geological and Geophysical Sciences, Princeton University, Princeton, NJ 08544 (U.S.A.)

${ }^{5}$ Current address: Department of Zoology, University of Wisconsin, Madison, WI 53706 (U.S.A.) through the production of variants, or indirectly, through a change in the hierarchical pattern of selection among variants (Bonner, 1982; Raff and Kauffman, 1983; Buss, 1987). Such changes may, in turn, introduce novelty within an evolving lineage. In this study, we examine the morphological consequences of an apparently heterochronic change in a planktic foraminiferal lineage during the Middle-Late Eocene. This interval is, on the whole, wellrepresented by deep sea sediments and is widely regarded as a time of major environ- 
mental change. In addition, these sediments include evidence for at least three separate extra-terrestrial impact events in the form of iridium anomalies, shocked minerals and geographically localized strewn fields of microtektite debris (Keller et al., 1987). Therefore, the Late Eocene fossil record of planktic foraminifera provides an opportunity to examine the creative role of environmental change, should it trigger a developmental response and the consequent potential for evolutionary novelty.

This investigations stems from the anecdotal observation of a qualitative reduction in overall test size between Middle and Late Eocene populations of the planktic foraminifera Subbotina linaperta (Finlay) at DSDP Site 612 (Keller, 1986). Keller et al. (1987) interpreted this size reduction as an example of dwarfism in addition to noting that this dwarfed population comprised an anomalously high proportion of the overall planktic foraminiferal fauna.

The traditional interpretation of dwarfing within an evolving lineage has been that of a passive response to deteriorating environmental conditions, with the corollary expectation of recovery from the dwarfed condition should the environment return to its previous state (Snyder and Bretsky, 1971; Marshall, 1974; Boltovskoy and Wright, 1976; Wassersug et al., 1979). In the fossil record, there are many welldocumented cases of conspecific size and associated shape changes, through dwarfing, such as those in insular and continental populations of mammals (e.g., Kurtén, 1959; Maglio, 1973; Marshall and Corruccini, 1978; Prothero and Sereno, 1982; Lister, 1989) and among various invertebrate groups (Tasch, 1953; Hallam, 1965; Snyder and Bretsky, 1971). The general interpretation of these data is that such dwarfing represents an ecological or densitydependent response with selection operating on body size. Alternatively, dwarfing may represent a simple consequence of selection involving either an acceleration in the timing of de- velopment (e.g., sexual maturation) or a negative displacement in the developmental stage at which attribute formation commences (Gould, 1977; Alberch et al., 1979; Alberch, 1982; Buss, 1987). In this latter instance, change in body size is a secondary or indirect effect of selection for changes in developmental timing.

Unfortunately, Site 612 contains an approximately $3 \mathrm{~m}$.y. depositional hiatus that separates the dwarfed Late Eocene $S$. linaperta populations from their larger Middle Eocene ancestors. Although this uncorformity must constrain any interpretation as to the relative timing of the dwarfing event, the fact that no noteworthy variation in overall test size for this species has been qualitatively observed in any of the deep sea sites that are relatively complete over this interval (Keller, 1983, 1986), suggests that this case of dwarfism may be geographically restricted. Also, based on the results of quantitative biostratigraphic analyses (Keller, 1986; Keller et al., 1987), it has been shown that high relative abundances of $S$. linaperta are associated with the dwarfing at this site indicating the possibility of a causal link between geographically restricted patterns of high relative abundance and small test size.

In order to distinguish between the ecophenotypic and developmental explanations for the dwarfing of this Late Eocene population, evidence in addition to that provided by the change in body size is needed. This evidence includes the quantitative characterization of morphological shape change and an unambiguous (and in this case fossilizable) character marking the attainment of sexual maturity by the organism as well as an explicit comparison of these patterns of developmentally mediated size and shape variation with those exhibited by coeval populations at different geographic localities. Consequently, we have examined the nature of quantitative morphological variation among Middle through Late Eocene populations of $S$. linaperta by summarizing relevant geometric, developmental and 
environmental data at three DSDP sites within the Atlantic Ocean basin in order to obtain a clear picture of both the temporal and spatial components of phenotypic variation.

\section{Materials and Methods}

Sediment samples were obtained from three DSDP sites: Site 612 in the western Atlantic, Site 94 in the Gulf of Mexico and Site 363 on the Walvis Ridge in the eastern South Atlantic (Fig. 1). Despite the fact that depositional hiatuses are present in each of these deep sea cores (Fig. 2), all three sites contain sediments referable to the Middle Eocene Morozovella lehneri Biozone and the Late Eocene Turborotalia cerroazulensis Biozone. Forty-three samples were used for the study, fifteen from Site 612 , sixteen from Site 94 and twelve from Site 363 (Fig. 2). Numbers of individual specimens obtained from the $>150 \mu \mathrm{m}$ size fraction comprising each sample are given in $\mathrm{Ta}$ ble II.

Patterns of morphometric variation in Middle and Late Eocene $S$. linaperta were quantified by locating a set of landmarks, including both homologous and relocatable points (Fig. 3 ). Interlandmark distances constructed from

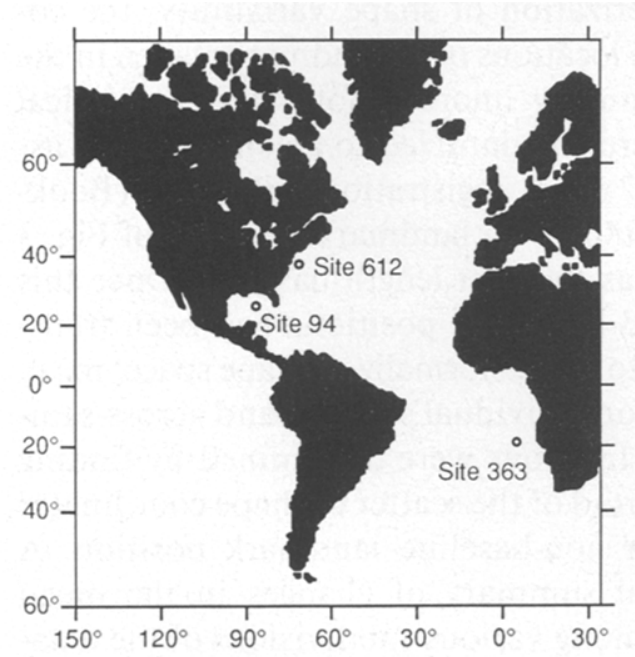

Fig. 1. Locations of DSDP Sites 612,94 and 363 within the Atlantic Ocean Basin.

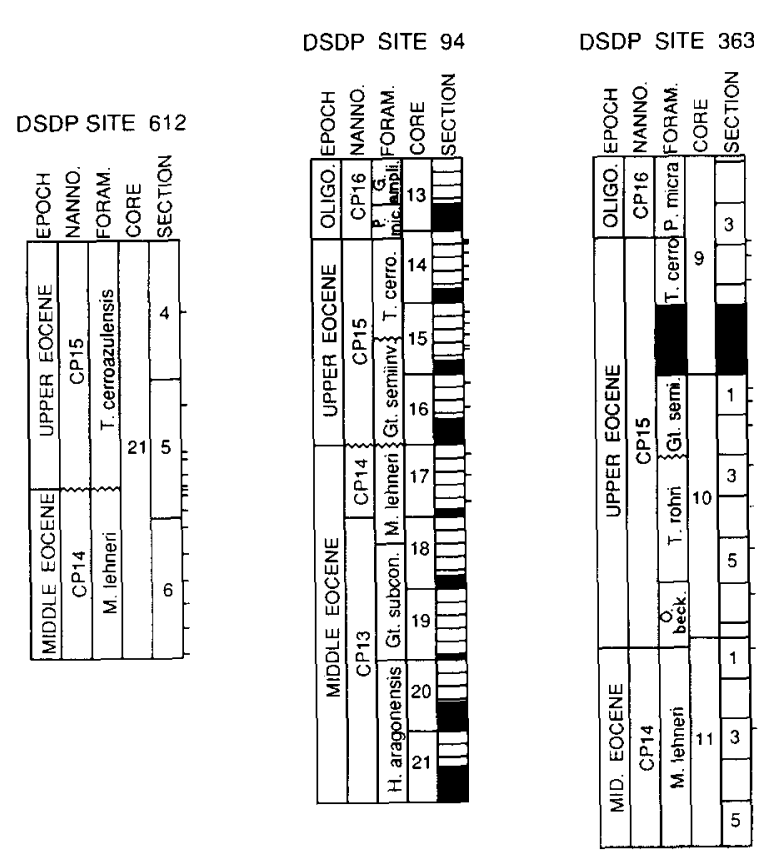

Fig. 2. Middle and Late Eocene stratigraphic sequences at DSDP Sites 612, 94 and 363. Sample positions are indicated by tick marks along the right margin of each stratigraphic column. Black intervals identify non-recovered core segments.

the landmark coordinates approximate the major and minor axes of the last three chambers, referred to as the ultimate $(u)$, penultimate ( $u-1$ ), and antepenultimate ( $u-2$ ) chambers. These distances include length $\left(l_{\mathrm{u}}\right)$ and height $\left(h_{\mathrm{u}}\right)$ of the ultimate chamber in umbilical view, length $\left(l_{\mathrm{u}-1}\right)$ and height $\left(h_{\mathrm{u}-1}\right)$ of the penultimate chamber in umbilical view, length $\left(l_{\mathrm{u}-2}\right)$ and height $\left(h_{\mathrm{u}-2}\right)$ of the antepenultimate chamber in umbilical view, apertural length in umbilical view ( $a l$ ), width of the ultimate chamber parallel to the coiling axis $\left(w_{\mathrm{u}}\right)$, width of the penultimate chamber parallel to the coiling axis $\left(w_{\mathrm{u}-1}\right)$, and width of the antepenultimate chamber parallel to the coiling axis ( $w_{\mathrm{u}-}$ 2).

Overall test size for each individual was estimated via principal component analysis (PCA) of the covariance matrix of log-transformed interlandmark distances for pooled $M$. lehneri and $T$. cerroazulensis zone data by 
Umbilical View

Lateral View
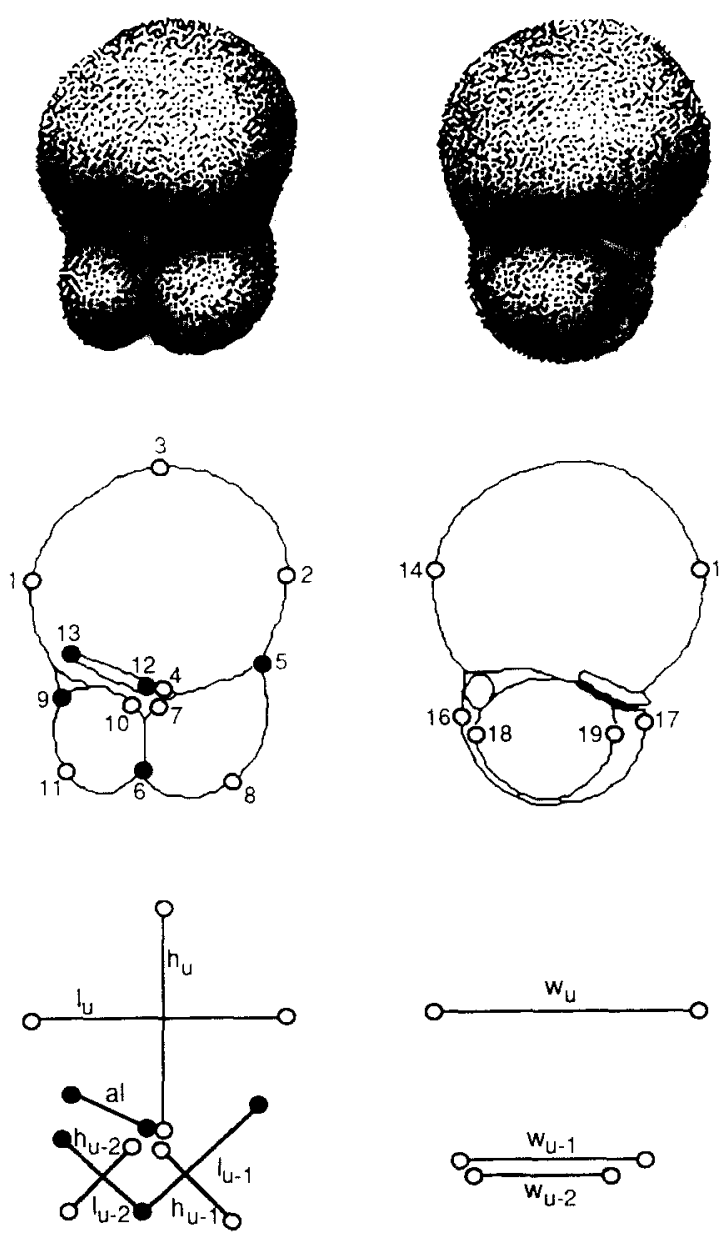

Fig. 3. Diagram of landmarks and constructed distances used to quantify morphometric variation in S. linaperta. Upper row, digital image of test in umbilical and lateral views; middle row, locations of landmarks: solid circles represent homologous points and open circles represent locations of local extrema; lower row, interlandmark distances constructed from landmark point locations. Abbreviations: $l=$ length, $h=$ height, $w=$ width, $u=$ ultimate chamber, $u-l=$ penultimate chamber, $u$ $2=$ antepenultimate chamber, $a l=$ apertural length.

projecting of each individual in the entire pooled dataset onto the first principal component (PCl). Interpretation of $\mathrm{PCl}$ as a generalized size axis is indicated by the fact that all variables load positively on this axis which lies within $1.00^{\circ}$ of $\mathrm{PC} 1$ for the pooled total dataset. Resulting size estimates are also highly correlated $(>0.95)$ with sample-independent univariate size measures (e.g., the distance variables themselves). For univariate regressions involving data from Site 612, the length of the penultimate chamber $\left(l_{\mathrm{u}-1}\right)$, was chosen as the most isometric univariate size estimator, based on its close approximation to the theoretical isometric loading for a 10 -variable principal component analysis (see Jolicouer, 1963).

Patterns of shape variation were summarized in two different and computationally unrelated ways. First, the orientation of each sitespecific $\mathrm{PCl}$ was examined to determined whether or not these principal axes of morphometric variation conformed to a strictly isometric model of shape change over the observed range of sizes. Next, the orientation of the higher principal components (PC2-PC10) of the pooled $M$. lehneri and $T$. cerroazulensis zone data for each site were corrected for the effects of between-sample size differences using Burnaby's method (Burnaby, 1966; Rohlf and Bookstein, 1987) and interpreted as representing size-independent shape contrasts between different regions of the test. Then, as an alternative to this multivariate morphometric characterization of shape variability, the coordinate locations of all landmarks taken in the taxonomically more informative umbilical view were standardized to a common size using the 2-point registration technique (Bookstein, 1986) with landmarks 1 and 2 of Fig. 3 serving as the unit length baseline. Once this set of 13 landmark positions had been transformed to a size-normalized shape space, mean shapes for individual samples and across-sample size fractions were determined by finding the centroid of the scatter of shape coordinates for each non-baseline landmark position. A graphical summary of changes in the mean shape among various subdivisions of the dataset was then obtained by superimposing these mean shapes and noting the resultant displace- 
ment of the non-baseline landmarks. Bookstein (1989) has also developed exact methods for quantitative characterization of the uniform and non-uniform components of these deformations and results of these analyses for the Site 612 S. linaperta data comprise a separate report (MacLeod and Kitchell, in press).

One potential difficulty in interpreting multivariate morphometric analyses is that while the resulting components or factors constitute a mathematically optimized redescription of the original data, they do not necessarily correspond to any particular model of developmental or phylogenetic change (see Blackstone, 1987a,b). In this investigation, however, we have attempted to maximize the biological information content (sensu Løvtrup and von Sydow, 1974) of the quantitative morphometric analysis by devising a measurement strategy that explicitly recognizes the chamber as the fundamental unit of foraminiferal development and test form. Therefore, each set of landmark coordinates locates the end points of the three semi-major axes of each individual chamber in the last whorl. These data encode variations in the degree of inflation and ellipticity of the last three growth increments (chambers) before the onset of gametogenesis which signals onset of the terminal ontogenetic stage while the additional measurement of apertural length provides an estimate of the size of the primary opening to the external environment for protoplasm during chamber formation.

Finally, stable oxygen and carbon isotopic analyses were conducted on samples of planktic ( $S$. linaperta and $T$. cerroazulensis) and benthic (Lenticulina sp. and Cibicidoides sp.) foraminifera collected from the $M$. lehneri and $T$. cerroazulensis zones at each site in order to assess the relative depth habitat of the planktic populations. For each sample, 10 randomly selected specimens were roasted in vacuo at $380^{\circ} \mathrm{C}$ for one hour and then reacted with anhydrous phosphoric acid at $55^{\circ} \mathrm{C}$ in an on-line gas extraction line coupled to the inlet of a VG
602 E ratio mass spectrometer. All analyses were performed at the Stable Isotope Laboratory of the University of Michigan and are reported on the PDB scale with conversions and corrections for ${ }^{18} \mathrm{O}$ in accordance with the procedure of Craig (1957).

\section{Results}

Relative abundance of Middle and Late Eocene S. linaperta

Although Keller et al. (1987) noted that the dwarfing of Late Eocene $S$. linaperta populations at Site 612 was accompanied by a dramatic increase this species' relative abundance, no explicit comparisons between the pattern of $S$. linaperta relative abundances at Site 612 and other coeval localities were presented at that time. However, when such comparisons are made (Fig. 4) several interesting patterns are evident. First, relative abundances of $S$. linaperta in the planktic foraminiferal fauna as a whole appear to have undergone an increase from the Middle to Upper Eocene at all comparable sites with the exception of Site 363 (though the Late Eocene mean relative abundance value of 0.59 is based on only 2 analyzed samples and therefore may not be statistically different from the Middle Eocene value of 1.68). This agrees with results of detailed relative abundance analyses conducted for Sites 219, 94, E67, 366 and 363, all of which show $S$. linaperta abundance acmes in either the T. cerroazulensis or Globigerinatheka semiinvoluta Biozones.

Second, relative to other geographic localities, Site 612 exhibits anomalously high abundances for $S$. linoperta during both the Middle Eocene $M$. lehneri and Upper Eocene T. cerroazulensis zones. This Site 612 fauna also appears to undergo a progressive decrease in planktic foraminiferal species richness during the Upper Eocene. The long-term persistence of the $S$. linaperta abundance anomaly off the northeastern coast of North America seems to 

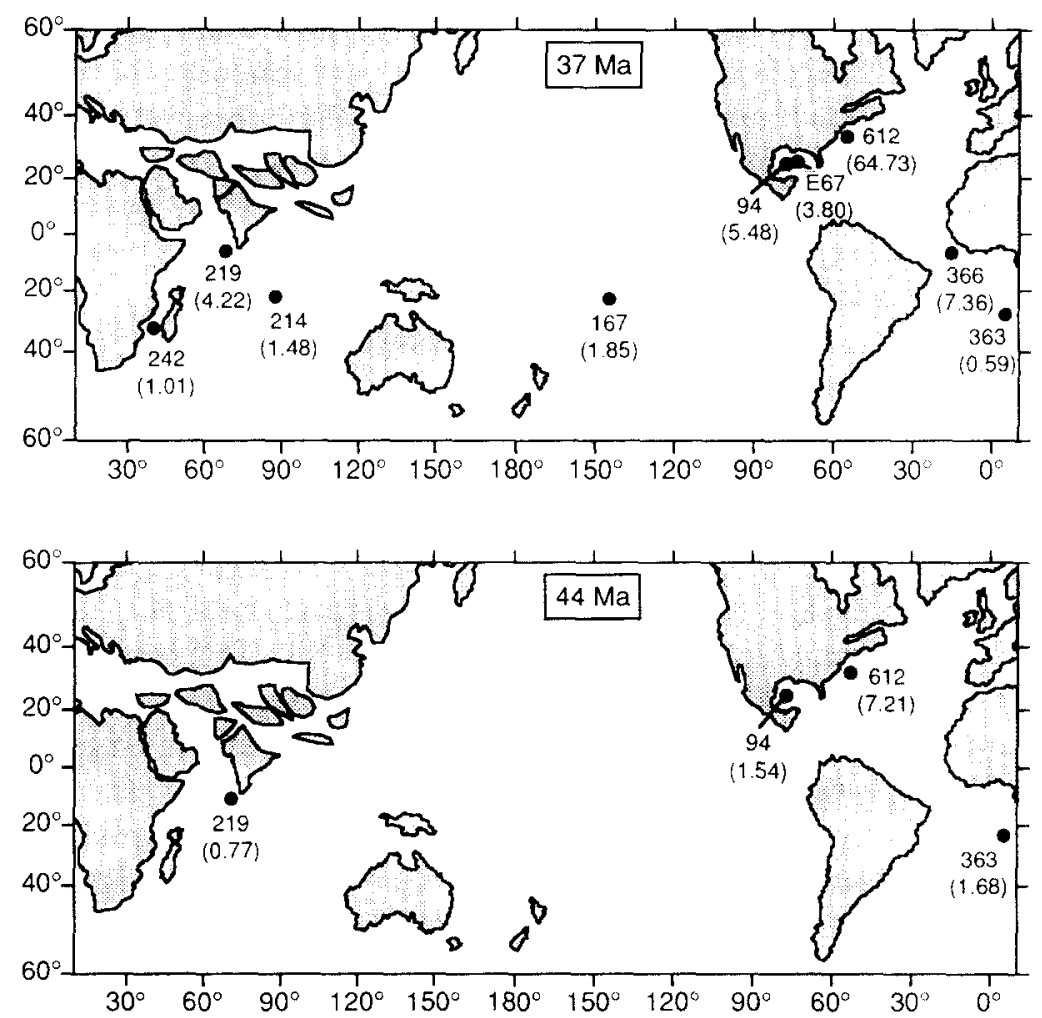

Fig. 4. Ocean drilling site locations and $S$. linaperta relative abundances (in parentheses) plotted on paleogeographic reconstructions of $M$. lehneri zone ( $44 \mathrm{Ma}$ ) and $T$. cerroazulensis zone ( $37 \mathrm{Ma}$ ) continental configurations. See text for discussion (Note: paleogeographic reconstructions obtained from the Terra Mobilis ${ }^{\mathrm{TM}}$ program of Denham and Scotese, 1987).

indicate that this population must have been somewhat isolated from the general circulation of the Gulf Stream, perhaps as a localized upwelling zone corresponding to a pronounced bend in the current system as it moved offshore.

Finally, the distinctiveness of $S$. linaperta abundance anomaly appears to have increased during the interval of time represented by the hiatus at Site 612. If the mean of the zonal relative abundance estimates for all localities other than Site 612 are regarded as a rough estimate of global background abundance for this species, then, during the Middle Eocene $M$. lehneri Zone, Site $612 S$. linaperta abundance was greater than background by a factor of over 5, while, during the Late Eocene $T$. cerroazulensis Zone, the Site $612 \mathrm{~S}$. linaperta abun- dance differential increased to a factor of almost 20.

\section{Stable isotope analyses}

Stable carbon $\left({ }^{13} \mathrm{C}\right)$ and oxygen $\left({ }^{18} \mathrm{O}\right)$ isotopic analyses were conducted on two planktic (S. linaperta, $T$. cerroazulensis s.s.) and two benthic forminiferal species (Lenticulina sp. and Cibicidoides sp.) from Site 612 to quantify possible changes in temperature, productivity and depth habitat between Middle and Late Eocene time. Figure 5 illustrates these results. Although the depositional hiatus limits our ability to draw firm conclusions regarding the character of Middle through Late Eocene environmental variation at this site, the environmental state (e.g., preferred depth habitat) 
of these faunas during the time intervals represented at Site 612 aids in understanding the ecologic and paleoceanographic implications of the observed abundance anomaly and test size decrease.

Late Eocene $\delta^{13} \mathrm{C}$ values of both planktic foraminiferal species indicate an enrichment of approx. $0.4 \%$ with respect to Middle Eocene values (Fig. 5). This suggests higher surface productivity during the Late Eocene as would be expected with the cooler temperatures and increased rates of turnover that characterize the Late Eocene (Shackleton and Kennett, 1975; Miller et al., 1987). The relatively depleted $\delta^{13} \mathrm{C}$ values just above the unconformity most likely reflects rapid burial of organic matter and locally reducing conditions as also indicated by abundant pyrite $(>10 \%)$ and low $\mathrm{CaCO}_{3}$ values $(<10 \%)$ (Keller et al., 1987). Benthic $\delta^{13} \mathrm{C}$ values also show anomalous enrichment immediately above the unconformity, though it is not clear whether this enrichment is due to increase bottom water productivity, turbidite deposition, or diagenetic alteration of the foraminiferal calcite.

Middle Eocene $\delta^{18} \mathrm{O}$ values indicate a separation of $1.0 \%$ to $1.2 \%$ between the isotopically light $T$. cerroazulensis and the heavier $S$. linaperta species suggesting that $T$. cerroazulensis lived closer to the surface (in warmer water) than $S$. linaperta (Fig. 5). In contrast, Late Eocene $\delta^{18} \mathrm{O}$ values for $S$. linaperta are relatively depleted and display a range of values that approximates those of Late Eocene $T$. cerroazulensis. Also, oxygen stable isotopic analyses of $T$. cerroazulensis zone $S$. linaperta from Sites 94 and $363\left(\delta^{18} \mathrm{O}\right.$ values equal to -0.027 and -0.026 respectively) show that the dwarfed S. linaperta populations at Site 612 exhibit markedly lower $\delta^{18} \mathrm{O}$ values than coeval populations in the Gulf of Mexico and the southern Atlantic.

These data suggest that the dwarfed Late Eocene Site $612 S$. linaperta populations may have lived closer to the surface at the time of gametogenesis than either their larger Middle Eocene ancestors or conspecific populations in the Gulf of Mexico and southern Atlantic; a shift in habitat that would be expected given the substantial nature of the size decrease. This shift in habitat may also have been augmented by the generally cooler Late Eocene water temperatures and associated shallowing of the thermocline as indicated by the $\delta^{18} \mathrm{O}$ values at Site 612 . Though a general cooling from the Middle through Late Eocene, as a result of the

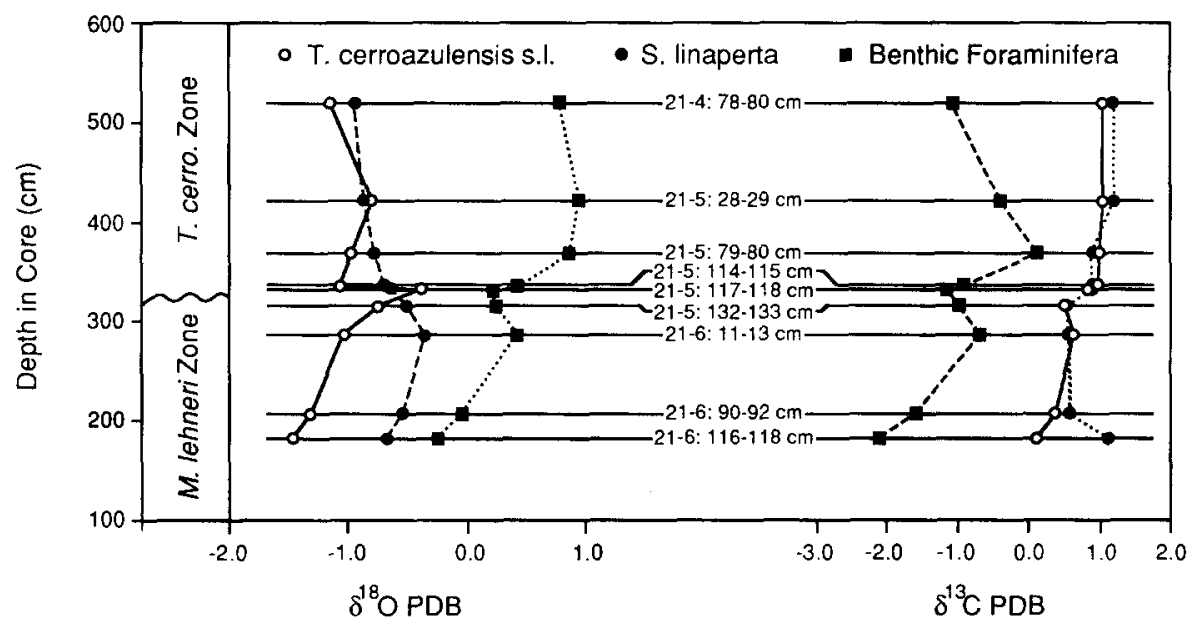

Fig. 5. Plots of $\delta^{18} \mathrm{O}$ and $\delta^{13} \mathrm{C}$ ratios for $S$. linaperta, T. cerroazulensis and benthic foraminifera (Cibicidiodes $\mathrm{sp}$. and Lenticulina sp.) from DSDP Site 612. Horizontal lines represent sampled intervals with exact sample locations given in the middle of the diagram. 
onset of circum-Antarctic circulation, is welldocumented in the paleoceanographic literature there is no evidence to indicate that the rate of cooling was particularly intense during the Middle through Late Eocene. Moreover, while the presence of the depositional hiatus prevents us from drawing any definite conclusions regarding the possible cause-effect relationship between the surface water thermal history of Site 612 and the dwarfing of S. linaperta, the temporal persistence of the local $S$. linaperta relative abundance anomaly, as well as the absence of coeval populations that have undergone either phenotypic or environmental shifts of comparable magnitude over this same time interval, provides evidence against interpreting the observed size reduction as a species-wide ecophenotypic response to the global Late Paleogene cooling of the world ocean.

\section{Quantitative test size analyses}

Univariate comparisons of the 10 linear distance variables for Middle and Late Eocene samples at Site 612 all display a marked shift toward smaller mean values in Late Eocene populations (Fig. 6). Similar shifts toward smaller mean values are also present in all $M$. lehneri and $T$. cerroazulensis Zone samples at

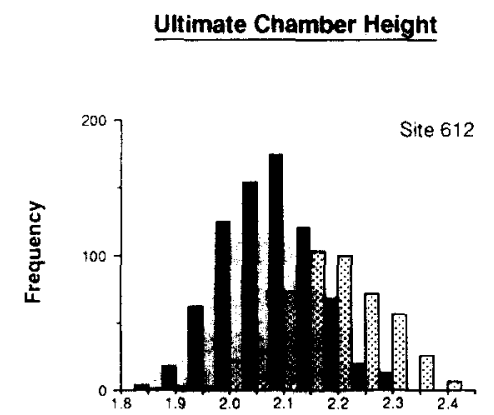

Ultimate Chamber Width

Penultimate Chamber Height
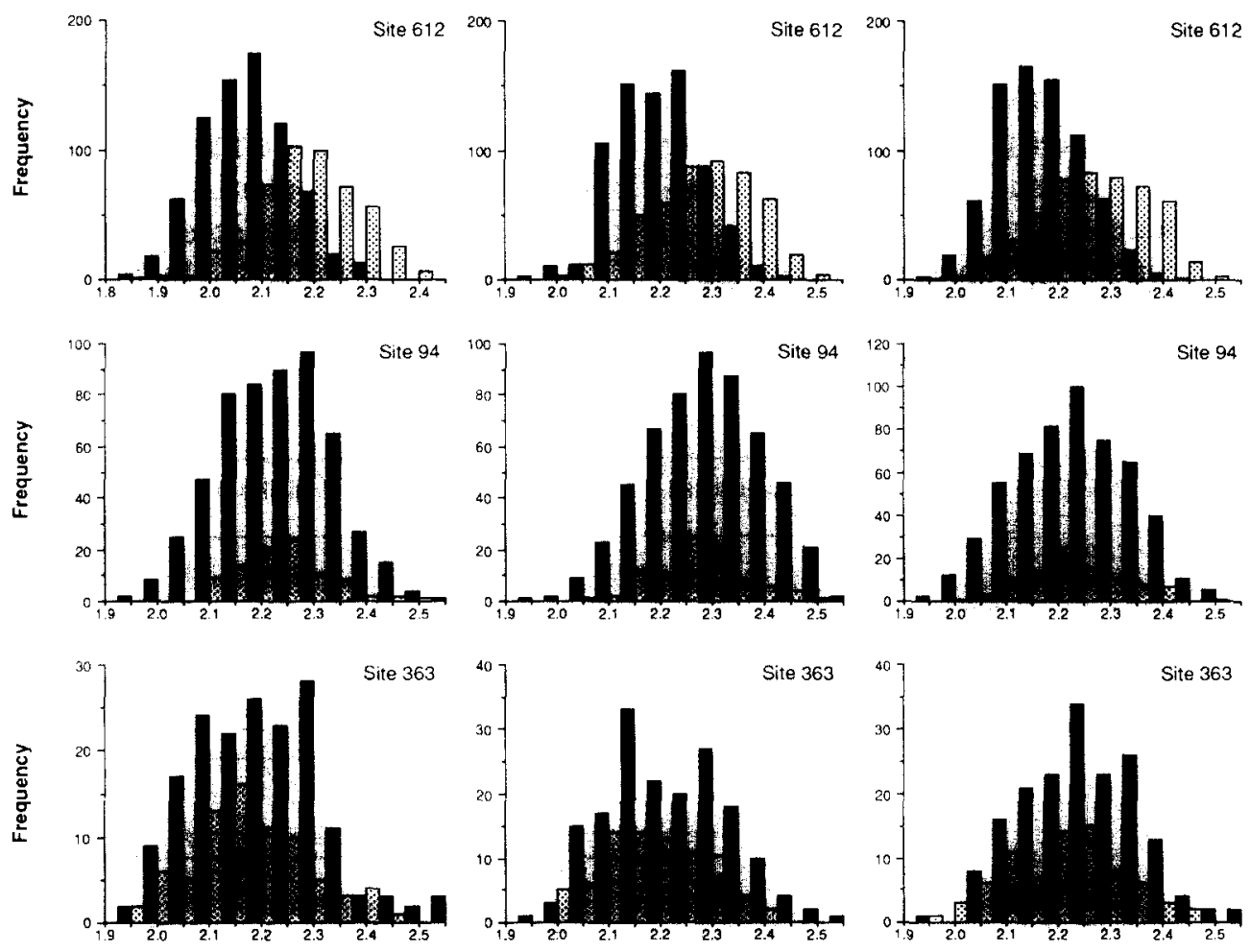

Log Distance $(\mu \mathrm{m})$

Fig. 6. Frequency distributions for three selected variables: ultimate chamber height $\left(h_{\mathrm{u}}\right)$, ultimate chamber width $\left(w_{\mathrm{u}}\right)$, and penultimate chamber height $\left(h_{\mathrm{u}-1}\right)$, at DSDP Site 612,94 and 363 illustrating the nature and extent of morphologic differentiation between $M$. lehneri Zone (stippled) and $T$. cerroazulensis Zone (black) populations. All variables transformed to $\log _{10}$. 
TABLE I

Variable loadings for various PCl (generalized size and shape) axes for S. linaperta interlandmark distance data

\begin{tabular}{|c|c|c|c|c|c|c|}
\hline Variable & $\begin{array}{l}\text { Site } 612 \\
(\lambda=85.22)\end{array}$ & $\begin{array}{l}\text { Site } 94 \\
(\lambda=78.53)\end{array}$ & $\begin{array}{l}\text { Site } 363 \\
(\lambda=84.79)\end{array}$ & $\begin{array}{l}\text { All sites/ } \\
\text { all zones } \\
(\lambda=82.73)\end{array}$ & $\begin{array}{l}\text { Mean of } \\
3 \text { sites }\end{array}$ & $\begin{array}{l}\text { All sites/ML } \\
\text { and } \mathrm{TC} \text { zones } \\
(\lambda=87.73)\end{array}$ \\
\hline$l_{\mathrm{u}}$ & 0.281 & 0.286 & 0.295 & 0.285 & 0.269 & 0.284 \\
\hline$h_{\mathbf{u}}$ & 0.307 & 0.273 & 0.261 & 0.290 & 0.283 & 0.296 \\
\hline$l_{\mathrm{u}-1}$ & 0.315 & 0.305 & 0.320 & 0.314 & 0.316 & 0.314 \\
\hline$h_{\mathrm{u}-1}$ & 0.315 & 0.329 & 0.318 & 0.319 & 0.324 & 0.318 \\
\hline$l_{\mathrm{u}-2}$ & 0.320 & 0.313 & 0.321 & 0.319 & 0.321 & 0.318 \\
\hline$h_{\mathbf{u}-2}$ & 0.330 & 0.346 & 0.330 & 0.335 & 0.338 & 0.334 \\
\hline al & 0.311 & 0.327 & 0.277 & 0.313 & 0.308 & 0.311 \\
\hline$w_{\mathbf{u}}$ & 0.302 & 0.311 & 0.313 & 0.305 & 0.311 & 0.306 \\
\hline$w_{\mathrm{u}-1}$ & 0.329 & 0.317 & 0.341 & 0.327 & 0.331 & 0.329 \\
\hline$w_{\mathrm{u}-2}$ & 0.346 & 0.348 & 0.373 & 0.350 & 0.359 & 0.349 \\
\hline
\end{tabular}

Site 94 , but only five variables $\left(h_{\mathrm{u}}, l_{\mathrm{u}-1}, l_{\mathrm{u}-2}\right.$, $w_{\mathrm{u}-1}, w_{\mathrm{u}-2}$ ) display a similar decrease in univariate sample mean at Site 363. Average percent differences between $M$. lehneri and T. cerroazulensis Zone sample means for all 10 linear distance variables are $26.90 \%$ for Site 612 , $6.97 \%$ for Site 94 and $3.77 \%$ for Site 363 .

Though univariate size analyses are informative, the summarization of size variation among biological entities usually necessitates the use of a multivariate size estimator such as PC1 score. For the $S$. linaperta data, use of this first principal component of the covariance matrix determined from the log-transformed linear distance data as a generalized size factor is indicated by the uniformly positive loadings of all 10 variables upon this axis as well as their striking similarity in magnitude (Jolicouer, 1963; see Table I). However, since depositional hiatuses have removed substantial portions of the Middle-Late Eocene stratigraphic record at Sites 612 and 94, several different $\mathrm{PC} 1$ 's are available for size estimation (e.g., total sample PC1, mean of within-site PC1's, PC1 of pooled $M$. lehneri and T. cerroazulensis zone data). Fortunately, the orientations of each of these axes quite similar (maximum orientational difference between any two axes in Table $\mathrm{I}<4.00^{\circ}$ ) thus minimizing the bias inherent in arbitrarily selecting a single axis to quantify size variation. Therefore, in order to insure temporal comparability among samples, size, for the purpose of this study, is defined as the relative location of a specimen along the first principal component of the $M$. lehneri and T. cerroazulensis Zone data pooled across all sites. Size estimates for each measured individual were obtained via projection of the individual onto this size axis and intrasample mean size estimates with associated $95 \%$ confidence intervals are presented in Table II.

Figure 7 summarizes Middle-Late Eocene $S$. linaperta test size variation at each of the three sites. These data show that the Site $612 \mathrm{~S}$. linaperta populations go from exhibiting relatively large mean test sizes during the Middle Eocene to exhibiting the smallest observed mean test sizes during the Late Eocene. Over this same time interval, the $S$. linaperta populations at Site 363 show predominantly random fluctuations in test size ending with a slight test size increase in Late Eocene $T$. cerroazulensis zone populations relative to the Middle Eocene $M$. lehneri zone ancestors while the Site 94 populations exhibit almost perfect size stasis between the M. lehneri and Gt. semiinvoluta zones followed by a relatively modest test size decrease between the Gt. semiinvoluta and $T$. cerroazulensis zones.

Overall, it seems clear that a dramatic change in mean test size occured at Site 612 sometime 
TABLE II

Mean test size ( $\mathrm{PC1}$ scores) and associated $95 \%$ confidence intervals for all measured samples

\begin{tabular}{|c|c|c|c|c|c|c|c|c|c|}
\hline \multirow{2}{*}{$\begin{array}{l}\text { Foram. } \\
\text { Biozones }\end{array}$} & \multicolumn{3}{|l|}{ DSDP Site 612} & \multicolumn{3}{|l|}{ DSDP Site 94} & \multicolumn{3}{|l|}{ DSDP Site 363} \\
\hline & $\begin{array}{l}\text { Sample } \\
\text { position } \\
\text { [Core-Sec:: } \\
\text { Depth }[\mathrm{cm}] \text { ) }\end{array}$ & $n$ & Mean size & $\begin{array}{l}\text { Sample } \\
\text { position } \\
\text { [Core-Sec:: } \\
\text { Depth }[\mathrm{cm}] \text { ) }\end{array}$ & $n$ & Mean size & $\begin{array}{l}\text { Sample } \\
\text { position } \\
\text { [Core-Sec.: } \\
\text { Depth }[\mathrm{cm}] \text { ) }\end{array}$ & $n$ & Mean size \\
\hline T. cerroazulensis & $21-4: 78-80$ & 82 & $6.52 \pm 0.06$ & $14-1: 89-93$ & 61 & $6.70 \pm 0.06$ & $9-3: 118-120$ & 78 & $6.78 \pm 0.06$ \\
\hline Zone & $\begin{array}{ll}21-5: & 28-29 \\
21-5: & 79-80 \\
21-5: & 86-87 \\
21-5: & 107-108 \\
21-5: & 114-115 \\
21-5: & 117-118\end{array}$ & $\begin{array}{r}159 \\
126 \\
153 \\
72 \\
104 \\
63\end{array}$ & $\begin{array}{l}6.65 \pm 0.04 \\
6.65 \pm 0.04 \\
6.63 \pm 0.04 \\
6.68 \pm 0.06 \\
6.61 \pm 0.04 \\
6.73 \pm 0.06\end{array}$ & $\begin{array}{l}14-1: 109- \\
113 \\
14-1: 140- \\
143 \\
14-2: 92- \\
100 \\
14-3: 100- \\
103 \\
14-4: 100- \\
103 \\
15-1: 100- \\
105 \\
15-2: 75-80 \\
15-3: 78-83\end{array}$ & $\begin{array}{r}57 \\
64 \\
61 \\
103 \\
48 \\
46 \\
42 \\
63\end{array}$ & $\begin{array}{l}6.77 \pm 0.06 \\
6.65 \pm 0.07 \\
6.84 \pm 0.06 \\
6.62 \pm 0.04 \\
6.86 \pm 0.05 \\
6.84 \pm 0.06 \\
6.74 \pm 0.07 \\
6.74 \pm 0.05\end{array}$ & $\begin{array}{l}9-4: \quad 38-40 \\
9-4: 138-140\end{array}$ & $\begin{array}{l}45 \\
50\end{array}$ & $\begin{array}{l}7.06 \pm 0.08 \\
6.76 \pm 0.05\end{array}$ \\
\hline G. semiinvoluta & & & & $15-4: 45-48$ & 54 & $6.68 \pm 0.06$ & $10-1: 55-57$ & 34 & $6.66 \pm 0.07$ \\
\hline Zone & & & & $\begin{array}{l}15-4: 106- \\
109 \\
16-1: 101- \\
104 \\
16-3: 80-85\end{array}$ & $\begin{array}{l}71 \\
48 \\
53\end{array}$ & $\begin{array}{l}6.75 \pm 0.06 \\
7.00 \pm 0.06 \\
7.06 \pm 0.07\end{array}$ & $\begin{array}{l}10-1: 100-102 \\
10-2: 38-40\end{array}$ & $\begin{array}{l}62 \\
68\end{array}$ & $\begin{array}{l}6.74 \pm 0.06 \\
6.79 \pm 0.05\end{array}$ \\
\hline $\begin{array}{l}\text { T. rohri } \\
\text { Zone }\end{array}$ & & & & & & & $\begin{array}{ll}10-3: & 38-40 \\
10-4: & 38-40 \\
10-5: & 38-40\end{array}$ & $\begin{array}{l}88 \\
44 \\
62\end{array}$ & $\begin{array}{l}6.75 \pm 0.05 \\
7.01 \pm 0.06 \\
6.99 \pm 0.05\end{array}$ \\
\hline $\begin{array}{l}\text { O. beckmanni } \\
\text { Zone }\end{array}$ & & & & & & & $10-6: \quad 38-40$ & 46 & $6.87 \pm 0.10$ \\
\hline M. lehneri & $21-5: 132-133$ & 59 & $7.02 \pm 0.08$ & $17-1: 100$ & 33 & $6.89 \pm 0.07$ & $11-1: 38-40$ & 40 & $6.88 \pm 0.10$ \\
\hline Zone & $\begin{array}{l}21-5: 139-140 \\
21-6: \quad 11-13 \\
21-6: \quad 38-40 \\
21-6: \quad 66-68 \\
21-6: \quad 90-92 \\
21-6: 116-118 \\
21-6: 145-147\end{array}$ & $\begin{array}{l}52 \\
74 \\
63 \\
43 \\
62 \\
79 \\
59\end{array}$ & $\begin{array}{l}7.24 \pm 0.07 \\
7.19 \pm 0.07 \\
7.16 \pm 0.06 \\
7.18 \pm 0.10 \\
7.05 \pm 0.08 \\
6.81 \pm 0.05 \\
6.91 \pm 0.06\end{array}$ & $\begin{array}{ll}102 & \\
17-3: & 34-36 \\
17-5: & 33-35\end{array}$ & $\begin{array}{l}30 \\
29\end{array}$ & $\begin{array}{l}6.80 \pm 0.09 \\
6.84 \pm 0.05\end{array}$ & $11-1: 38-40$ & 36 & $6.76 \pm 0.06$ \\
\hline
\end{tabular}

during the interval represented by the depositional hiatus and that this phenotypic change was a persistent feature of all subsequent planktic foraminiferal assemblages existing at this geographic locality (Table II) as well as being accompanied by corresponding changes in this population's relative abundance and preferred depth habitat. A qualitative illustration of the nature of this mean test size decrease is provided by Fig. 8 . In addition, from these data it might also be suggested that Middle Eocene $M$. lehneri Zone S. linaperta populations were anomalously large relative to conspecific populations in the Gulf of Mexico and 


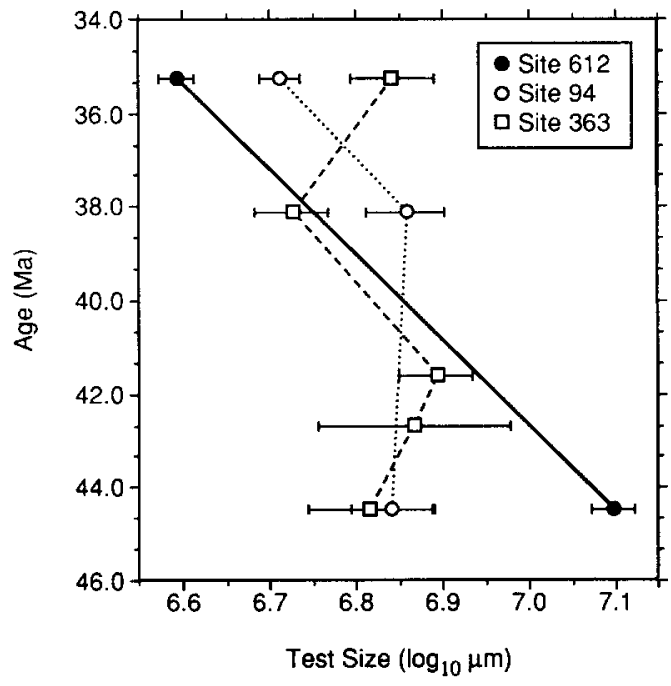

Fig. 7. Mean test sizes (PCl scores) and associated 95\% confidence intervals for Middle through Late Eocene populations of $S$. linaperta at Site 612,94 and 363.

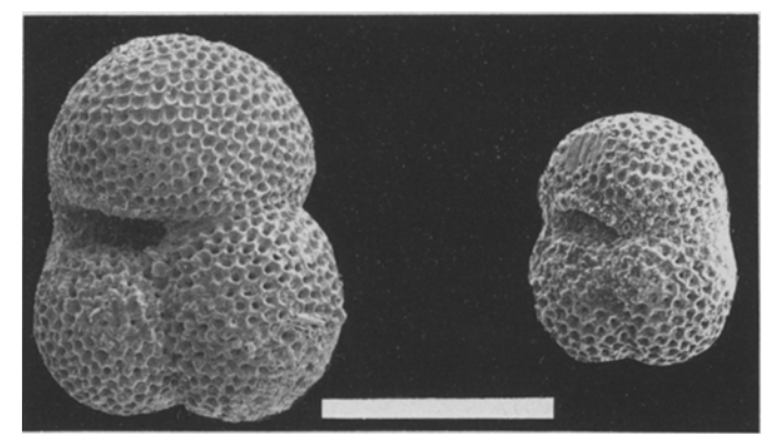

Fig. 8. Representative (mean-sized) specimens of $M$. lehneri zone populations (left) and $T$. cerroazulensis zone populations (right) of $S$. linaperta illustrating the overall magnitude of test size change and character of test shape changes. Scale bar $=200 \mu \mathrm{m}$.

southern Atlantic. However, owing to the limited nature of the Middle Eocene database in terms of geographic coverage and the failure of the isotopic analyses to reveal any noticeable change in depth habitat for these Middle Eocene populations, we prefer to provisionally regard the Middle Eocene Site $612 \mathrm{~S}$. linaperta populations as comprising a more-or-less typical pattern of geographically mediated phenotypic variability from which the Late Eocene $T$. cerroazulensis Zone populations have de- parted in terms of mean size, relative abundance and depth habitat.

Finally, we do not presently regard the small (approx. 7\%) mean test size decrease exhibited by the $T$. cerroazulensis Zone $S$. linaperta populations at Site 94 to be large enough to warrant their identification as 'dwarfed' despite the fact that they are, without a doubt, slightly smaller than those populations comprising the underlying Gt. semiinvoluta Zone. As can be seen in the data from Site 363 (Fig. 7, Table II), size fluctuations of similar magnitude have occurred within a non-directional pattern of test size variation. Nevertheless, we do note that the pattern of size variation at Site 94 may have important implications for understanding the probable timing of size change at Site 612 as discussed below.

In terms of identifying the cause of the observed size decrease in Middle through Late Eocene $S$. linaperta populations at Site 612 , both mechanical sorting of the planktic foraminiferal fauna by current action and ecophenotypic stunting of the foraminiferal faunal assemblage as a whole due to temporarily adverse environmental conditions are ruled out as possible explanations due to: (i) the temporal persistence of the size reduction, (ii) the presence of a wide range of foraminiferal test sizes in the Late Eocene Site 612 faunas as a whole, and (iii) the fact that other species of both planktic and benthic foraminifera at this site qualitatively appear to exhibit a normal range of test sizes. Similarly, there is no evidence to suggest that the diminutive Late Eocene $S$. linaperta specimens are allochthonous elements of the faunal assemblage that have been introduced into this environmental setting by redeposition (e.g., associated benthic and planktic foraminiferal species indicate normal marine hemipelagic deposition with no other obviously reworked elements ).

Having eliminated mechanical sorting, reworking and environmental stunting as possible explanations we proceed to an analysis of developmental variation in order to determine 


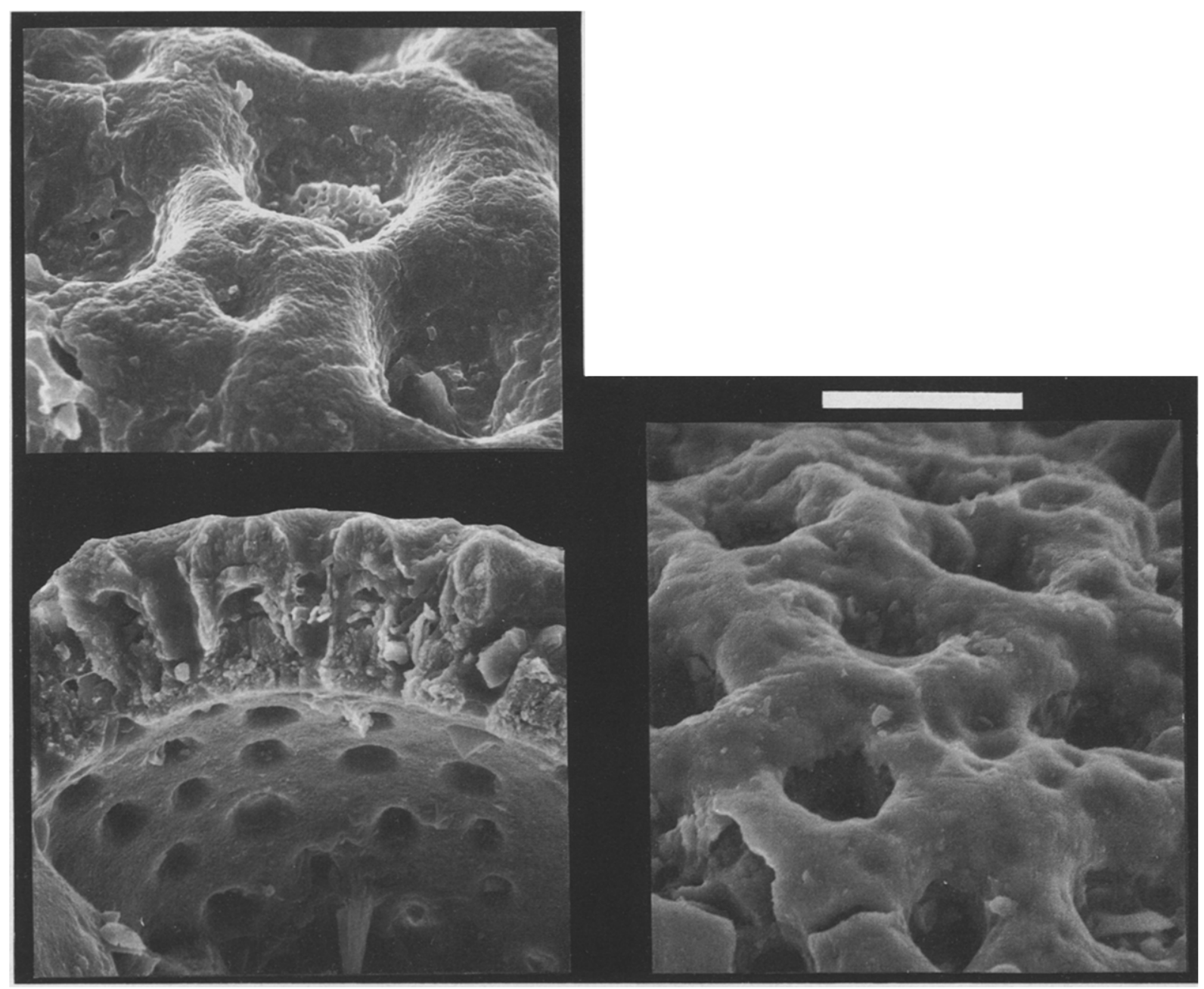

Fig. 9. Surficial wall texture of a representative mean-sized $T$. cerroazulensis Zone $S$. linaperta specimen from DSDP Site 612 exhibiting microstructural features typical of gametogenic calcification including: spine holes (upper left), a smooth veneer-like layer of calcite draping into pores (lower left and lower right), and parallel-sided pore throats (lower left); see text for further discussion. Scale bar $=8.6 \mu \mathrm{m}$ (upper left), $17.6 \mu \mathrm{m}$ (lower left), $15.0 \mu \mathrm{m}$ (lower right).

if the dwarfed fauna is predominantly composed of juvenile (in which case the fauna could not be correctly described as 'dwarfed') or adult specimens. In spinose planktic foraminifera such as S. linaperta (see Blow, 1979), gametogenesis signals the attainment of sexual maturity and is phenotypically expressed by deposition of a thick layer of calcite on the surface of the test (Bé, 1980, 1982; Hemleben and Spindler, 1983; Brummer et al., 1987). The microstructure of this gametogenically calcified layer is distinguishable from the underly- ing ontogenetically calcified test wall by the presence of broad interpore ridges, spine holes (a consequence of resorption of the spine bases), constricted parallel-sided pore basins, and a smooth veneer of gametogenic calcite that drapes over the entire test surface.

Scanning electron microscopy was used to determine the developmental state of a number of randomly selected individuals from the T. cerroazulensis Zone populations at Site 612 and in virtually all cases, the characteristic microstructural features of gametogenic calcifi- 
cation were able to be identified (see Fig. 9). This indicates that despite the reduced size of these specimens, they do represent sexually mature, adult morphologies. Thus, the observed difference in mean size of the $T$. cerroazulensis Zone versus $M$. lehneri Zone populations involves a shift in the mean size at gametogenesis (the offset $(\beta)$ signal of Alberch et al., 1979).

\section{Quantitative test shape analyses}

Three alternative modes of developmental variation involve a disruption in the onset signal, offset signal or rate of developmental change resulting in a reduction in mean body size (Gould, 1977; Alberch et al., 1979; McNamara, 1986). First, the growth rate might be decreased such that an adult descendant will be produced that exhibits the same shape as the adult ancestor but at a smaller body size. This process is termed proportional dwarfing. Alternatively, a change may occur in the age at which a structure (e.g., the test) begins its ontogeny; a pattern that also yields (provided the growth offset signal and growth rate remain constant) an adult descendant that has the same shape but smaller body size than its adult ancestor. This process is termed pre-displacement. In principal, pre-displacement can be distinguished from proportional dwarfing in that the latter necessarily implies a decrease in the growth rate between ancestor and descendant organisms while the former does not. However, accurate growth rates are exceedingly difficult to measure in fossil material and, in practice, a variety of alternative growth rate, growth offset signal, and growth onset age configurations can be envisioned that may be difficult to sort out using data typically obtainable from preserved test morphology. Finally, body size reduction can be developmentally induced via a decrease in the period during which the growth of a structure takes place; such as the early cessation of growth due to precocious sexual maturation. This process is termed progenesis and results in the production of an adult descendant that exhibits both a smaller body size and the shape of a juvenile ancestor. In all cases, explicit shape as well as size comparisons are necessary in order to identify the predominant developmental (heterochronic) mode.

A preliminary test for shape similarly compares the within-site $\mathrm{PCl}$ orientations of the pooled $M$. lehneri and $T$. cerroazulensis Zone data for significant deviation from an isometric orientation (all coefficients equal; see Jolicouer, 1963). Angular deviations in S. linaperta $\mathrm{PC} 1$ orientations at Sites 612, 94 and 363 for the $M$. lehneri and T. cerroazulensis zone data (pooled separately) with respect to the theoretical axis of isometry range from $3.41^{\circ}$ to $7.13^{\circ}$ and Anderson's (1963) test for significance of these deviations indicates that the zonal PC1's at each site are different $(p<0.05)$ from multivariate isometry. In addition, this pattern of multivariate allometry appears to be consistent feature of each measured sample with angular differences in $\mathrm{PCl}$ orientation between the individual stratigraphic samples exhibiting only moderate amounts of variation ranging from $3.15^{\circ}$ to $13.09^{\circ}$ for Site 612 , $3.47^{\circ}$ to $19.94^{\circ}$ for Site 94 and $3.14^{\circ}$ to $12.65^{\circ}$ for Site 363 .

While orientation of the multivariate size axis (PC1) among the three sites appears to be remarkably consistent, comparisons among the predominant multivariate shape axes (PC2 and PC3) reveal systematic patterns of shape differentiation between geographic localities (Table III). These two axes, together with the corresponding $\mathrm{PCl}$ account for $92.86 \%$ (Site 612 ), $86.84 \%$ (Site 94), and 92.29\% (Site 363 ) of the observed morphological variability. Also, adjustment of PC 2 and PC 3 orientations over all three sites via the Burnaby method (Table III) resulted in very slight rotations (from $0.27^{\circ}$ to $1.70^{\circ}$ for $\mathrm{PC} 2$ and from $0.05^{\circ}$ to $14.70^{\circ}$ for $\mathrm{PC} 3$ ) confirming that only small differences in the orientations of the sample-specific principal shape axes are pres- 
TABLE III

Variable loadings for the raw and Burnaby adjusted PC2 and PC 3 of the pooled $M$. lehneri and $T$. cerroazulensis Zone S. linaperta interlandmark distance data

\begin{tabular}{|c|c|c|c|c|c|c|}
\hline \multirow[t]{2}{*}{ Variable } & \multicolumn{3}{|l|}{ PC2 } & \multicolumn{3}{|c|}{ PC2 (Burnaby) } \\
\hline & $\begin{array}{l}\text { Site } 612 \\
(\lambda=4.48)\end{array}$ & $\begin{array}{l}\text { Site } 94 \\
(\lambda=7.12)\end{array}$ & $\begin{array}{l}\text { Site } 363 \\
(\lambda=3.78)\end{array}$ & Site 612 & Site 94 & Site 363 \\
\hline$l_{\mathrm{u}}$ & -0.018 & -0.077 & -0.129 & -0.026 & -0.081 & -0.131 \\
\hline$h_{u}$ & -0.049 & -0.151 & 0.045 & -0.056 & -0.155 & 0.044 \\
\hline$l_{\mathrm{u}-1}$ & 0.133 & 0.111 & 0.083 & 0.123 & 0.107 & 0.081 \\
\hline$h_{u-1}$ & 0.180 & 0.239 & 0.041 & 0.170 & 0.235 & 0.040 \\
\hline$l_{\mathrm{u}-2}$ & 0.025 & 0.043 & -0.067 & 0.016 & 0.038 & -0.069 \\
\hline$h_{\mathrm{u}-2}$ & 0.055 & 0.138 & -0.100 & 0.045 & 0.134 & -0.101 \\
\hline al & -0.906 & -0.876 & -0.795 & -0.915 & -0.880 & -0.796 \\
\hline$w_{u}$ & 0.070 & 0.003 & -0.014 & 0.061 & -0.001 & -0.015 \\
\hline$w_{\mathrm{u}-1}$ & 0.153 & 0.147 & 0.237 & 0.143 & 0.142 & 0.236 \\
\hline$w_{\mathrm{u}-2}$ & 0.306 & 0.302 & 0.520 & 0.295 & 0.297 & 0.518 \\
\hline \multirow[t]{2}{*}{ Variable } & \multicolumn{3}{|l|}{$\mathrm{PC} 3$} & \multicolumn{3}{|c|}{ PC3 (Burnaby) } \\
\hline & $\begin{array}{l}\text { Site } 612 \\
(\lambda=3.16)\end{array}$ & $\begin{array}{l}\text { Site } 94 \\
(\lambda=4.43)\end{array}$ & $\begin{array}{l}\text { Site } 363 \\
(\lambda=3.03)\end{array}$ & Site 612 & Site 94 & Site 363 \\
\hline$l_{\mathrm{u}}$ & -0.289 & -0.294 & -0.287 & -0.298 & -0.294 & -0.292 \\
\hline$h_{u}$ & -0.648 & -0.597 & -0.612 & -0.656 & -0.597 & -0.617 \\
\hline$l_{\mathrm{u}-1}$ & 0.053 & -0.105 & 0.109 & 0.043 & -0.105 & 0.104 \\
\hline$h_{\mathrm{u}-\mathrm{i}}$ & 0.226 & -0.049 & 0.429 & 0.216 & -0.049 & 0.424 \\
\hline$l_{\mathrm{u}-2}$ & 0.258 & 0.277 & 0.301 & 0.248 & 0.277 & 0.296 \\
\hline$h_{\mathrm{u}-2}$ & 0.501 & 0.520 & 0.389 & 0.491 & 0.520 & 0.384 \\
\hline al & 0.118 & 0.246 & -0.067 & 0.109 & 0.246 & -0.071 \\
\hline$w_{u}$ & -0.326 & -0.345 & -0.305 & -0.336 & -0.346 & -0.310 \\
\hline$w_{u-1}^{\prime}$ & -0.039 & 0.053 & 0.286 & -0.049 & 0.053 & 0.023 \\
\hline$w_{u-2}$ & -0.055 & 0.117 & -0.079 & 0.044 & 0.117 & -0.085 \\
\hline
\end{tabular}

\section{TABLE IV}

Pairwise comparison of homogeneity in site-specific S. linapert $a$ interlandmark distance covariance matrices

\begin{tabular}{llllll}
\hline Sites & \multicolumn{2}{l}{ T. cerro Zone } & & \multicolumn{2}{l}{ M. lehneri Zone } \\
\cline { 2 - 3 } \cline { 5 - 6 } & $\beta^{2}$ & $\mathrm{~B}^{2}$ & & $\beta^{2}$ & \multicolumn{1}{c}{$\mathrm{B}^{2}$} \\
\hline $612-94$ & 1.855 & $164.74^{*}$ & 0.859 & $302.89^{*}$ \\
$612-363$ & 1.150 & $362.49^{*}$ & 2.566 & $80.92^{*}$ \\
$94-363$ & 1.170 & $298.49^{*}$ & 2.673 & $111.09^{*}$ \\
\hline
\end{tabular}

degrees of freedom $=55 ; *$ significant at $P<0.001$.

ent in the data and insuring that the following interpretations have not been biased by between-sample size variation.

PC2 loadings are generally similar at all sites with apertural length exhibiting the highest loading at each site. In general, PC2 at each site represents a shape contrast between decreasing apertural length and increasing penultimate and antepenultimate chamber width with the rate of apertural length decrease being greatest at Site 612 while the rate of chamber width increase is greatest at Site 363. Angular orientations of the $\mathrm{PC} 2$ axes indicate that, in terms of this component of shape variation, Sites 612 and 94 are more similar $\left(10.02^{\circ}\right)$ to each other than either is to Site $363\left(22.16^{\circ}\right.$ and $26.64^{\circ}$ respectively).

Patterns of variable loadings on PC 3 are also similar between sites in terms of those variables that exhibit relatively high coefficients $(> \pm 0.25)$ on this shape axis. At all sites PC3 predominantly represents a contrast between 

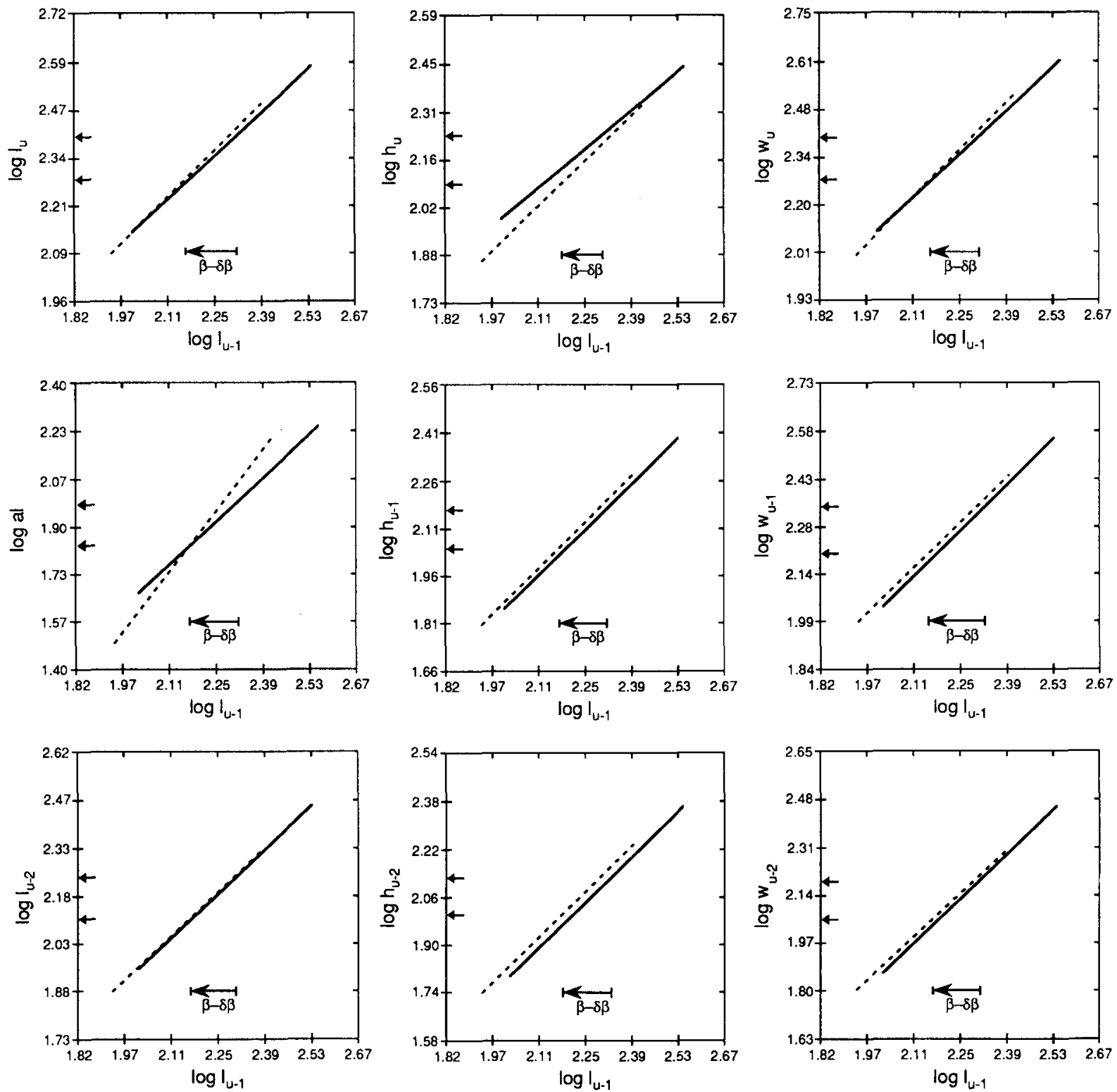

Fig. 10. Univariate allometric regressions (major axis) for chamber distance measurements vs. penultimate chamber length $\left(l_{\mathrm{u}-1}\right)$. Solid lines represent $M$. lehneri Zone populations, dashed lines represent $T$. cerroazulensis Zone populations. Small arrows along $y$-axis indicate $M$. lehneri Zone (upper arrow) and $T$. cerroazulensis Zone (lower arrow) means with the magnitude and direction of the mean offset in test size $(=\beta$ offset of Alberch et al., 1979) indicated by the lower arrow $(\beta-\delta \beta)$ in each plot.

relatively decreasing ultimate chamber size (especially with respect to chamber height) and increasing antepenultimate chamber length and height. It should be noted, however, that this contrast represents relative directions of shape variability and despite the strongly neg- ative loadings for the ultimate chamber dimensions on this axis, no kummerform individuals were observed in the measured populations from any of the three analyzed sites.

A quantitative overview of these patterns of 


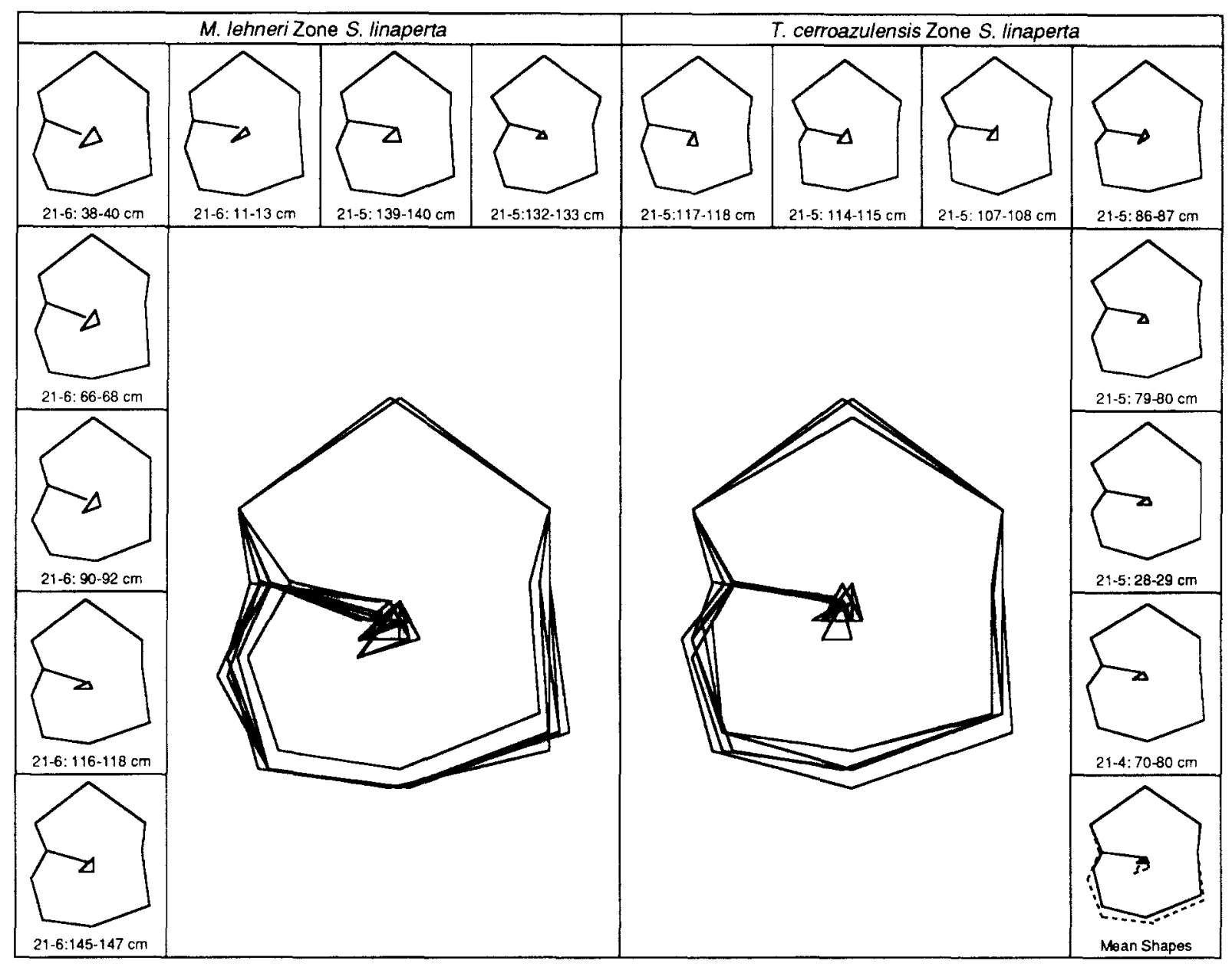

Fig. 11. Size-normalized mean configurations of shape coordinates for landmark points measured in umbilical view for each of the sampled $S$. linaperta populations at DSDP Site 612. Central overlays represent the character and magnitude of shape variation within $M$. lehneri Zone (left) and $T$. cerroazulensis Zone (right) populations. Note the clear shape differentiation exhibited by the $T$. cerroazulensis Zone populations in terms of trochospiral coiling parameters and chamber ellipticity.

similarity and difference can be gained via a series of pairwise analyses that were conducted in order to assess the degree of homogeneity among the respective within-site pooled covariance matrices (Table IV). These analyses determine differences in orientation and length of the principal variational axes PC1, PC2 and PC3 using the Anderson (1963) test (see Reyment, 1969 for examples). All between-site comparisons show significant $(p<0.001)$ differences in homogeneity of the covariance matrices signalling that statistically significant size and shape differences are present between all geographic localities in both the $M$. lehneri and $T$. cerroazulensis Zones.

Once multivariate analyses have identified the major features of shape variation, it is informative to examine the allometric behaviour of the variables in isolation. Figure 10 shows the results of a series of univariate allometric regression analyses on $M$. lehneri and $T$. cerroazulensis Zone mixed cross-sectional data from Site 612. For 8 out of the 10 linear distance variables, the dominant pattern of vari- 


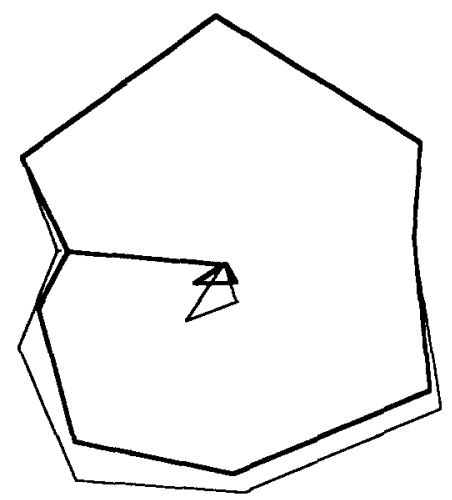

Fig. 12. Comparison of global mean shape coordinate configurations for the thirteen landmarks measured in umbilical view for $M$. lehneri Zone (thin line) and $T$. cerroazulensis Zone (thick line) populations.

ation includes a decrease in the size at which sexual maturity is attained in these Late Eocene populations of $S$. linaperta while maintaining essentially the same shape (in terms of relative test feature size) as smaller-sized individuals of the ancestral $M$. lehneri Zone populations. Prominant exceptions to this pattern are ultimate chamber height $\left(h_{\mathrm{u}}\right)$ and apertural length (al). Since test size (as opposed to chamber number) has been determined to be the best index of developmental stage in modern planktic foraminifera (Brummer et al., 1987; Hemleben et al., 1989), similarly in the slopes and intercepts of the majority of these allometric regressions suggests that precocious gametogenesis has resulted in the production of smaller Late Eocene forms that closely correspond to an earlier developmental stage in the ancestral ontogeny, thus conforming to the expected pattern of progenesis (Alberch et al., 1979; Buss, 1987). For most variables, there is also a slight increase in slope coincident with the decrease in the overall test size. Exceptions are width of the penultimate and antepenultimate chambers parallel to the coiling axis, both of which exhibit decreases in growth rate.

A conceptually simpler way of summarizing shape variability in these populations is to compare the mean landmark configurations of individual samples after they have been size- normalized using the 2-point registration method. Figure 11 illustrates results of this landmark-based analysis for the Site 612 data. Although patterns of overall shape variation appear relatively uniform, some distinct differences in mean landmark configuration are evident. These include a relative shortening in height of the penultimate and antepenultimate chambers and a relative decrease in the size of the umbilical area in the Late Eocene populations (Fig. 12). The observed changes in overall test geometry that characterize the $T$. cerroazulensis Zone populations are interpreted to be the result of an overall tightening of the trochospiral coil. In addition, the fact that such a tightening, occurring coincident with the substantial shift toward smaller mean size, is also exhibited by smaller-sized individuals of the $M$. lehneri Zone populations (MacLeod and Kitchell, in press ) and that gametogenesis appears to be preferentially taking place in shallower waters (as discussed above) that were most probably inhabited by sexually immature individuals in the Middle Eocene both serve to support the identification of progenesis as the predominant mode of heterochronic variation between Middle and Late Eocene $S$. linaperta at this locality.

\section{Discussion}

Among a large variety of modern and fossil organisms, progenesis is often found to characterize species or populations that, for one reason or another, inhabit unstable environments or manage to colonize a depauperate ecospace (e.g., survivors of a local population crash, island populations ). In both of these instances, selection favors short generation time leading to rapid increase in population size, reduced interspecific competition due to the local superabundance of resources, and the 'unbinding' of a strong linkage between morphology and environmental variation through a redirection of selection pressure away from the phenotype per se and toward devel- 
opmental or life history characteristics (Gould, 1977, 1989). In addition, McNamara (1989) has noted that progenesis cannot be an effective evolutionary strategy unless there is (i) an appreciable morphological change during ontogeny in the sense that allometries must substantially differ from isometry, or (ii) an ecological separation between juveniles and adults so that the progenetic dwarfs realize an immediate selective advantage in terms of niche partitioning along with the consequent opportunity for continued ecological and ultimately genetic isolation. Nevertheless, evolutionary change is a chancy game that is more often lost than won and, as Gould (1969) has noted in reference to paedomorphic populations of Bermuda land snails, it is commonly the case that such changes deprive the juvenilized morphologies of valuable attributes and in so doing often exchange short-term ecological success for long-term extinction resistance.

The historical record of changes in Late Eocene $S$. linaperta morphology, relative abundance and preferred depth habitat at Site 612 exhibit a remarkable conformance to this emerging evolutionary/ecological model for paedomorphosis in general and progenesis in particular. The environmental perturbation that caused the morphological changes in $S$. linaperta at Site 612 also effected the overall planktic foraminiferal fauna by reducing both the relative abundance of associated species and the species richness of the fauna as a whole. At the same time, Keller (1986) and Keller et al. (1987) note that the sediment layer containing microtektites at Site 612 also contains a high abundance of pyrite (10-15\%) that suggests the temporary existence of reducing conditions at this locality possible as a result of increased productivity and/or mass mortality of marine plankton. In either case, Late Eocene $S$. linaperta populations would have been presented with an environment that was at least semi-isolated from the gyral circulation of the Gulf Stream and contained reduced numbers of local planktic foraminiferal competitors.
Also, it is interesting to note that while planktic foraminiferal species richness continued to decline throughout the $T$. cerroazulensis zone at Site 612 (from 23 species just above the microtektite layer to 2 species $1.8 \mathrm{~m}$ above the microtektite layer ), within these same samples $S$. linaperta exhibits both an increase in relative abundance (from $68.5 \%$ to $87.0 \%$ ) and a further decrease in mean test size (Table II).

Since size was evidently not the direct target of the selective pressures that produced the progenetically dwarfed Late Eocene $S$. linaperta fauna at Site 612 , what was gained through this process of selection? Shape variability for the species as a whole was increased by the developmental alteration of this population; but not by much. After progenesis, adult $S$. linaperta were, on the whole, a bit smaller, a bit more tightly coiled, and had a slightly more ellipsoidal ultimate chamber. Such relatively subtle changes in morphology were ensured for virtually any conceivable heterochronic variant in that all analyzed populations exhibit a very close approximation of within-site $\mathrm{PC} 1 \mathrm{~s}$ to the hypothetical axis of isometry (Table I). But it is quite likely that these concomitant shape changes were also adaptively neutral byproducts of selection for a significant change in life history rather than morphological type. The most fundamental change that the progenesis of this population wrought was in dispensing with the evident need to pass the latter stages of the life cycle within the deeper intermediate water planktic foraminiferal fauna. Oxygen isotopic data indicates that the progenetically dwarfed Site 612 population was composed entirely of surface dwellers that had completely abandoned the intermediate water gametogenesis of their ancestors and in so doing altered what had been an apparently fundamental attribute of this species (Keller, 1983; Keller and MacLeod, in press).

Any evolutionary processes capable of successfully engendering such dramatic changes in a species' ecology must have tremendous ma- 
croevolutionary potential. For $S$. linaperta, this potential was not realized due to the extinction of the Site 612 local population near the Eocene-Oligocene boundary. However, synoptic analysis of the fossil record indicates that this has not always been the case and there is an emerging consensus that progenesis may have played a much larger macroevolutionary role than has traditionally been envisioned. For example, McNamara (1989) argues that progenesis has played an important role in the evolutionary histories of amphibians and brachiopods not because morphological differences between juveniles and adults are great, but because the ecological differences between juveniles and adults are great (from aquatic to terrestrial organisms in the case of amphibians and with respect to height above the substrate in certain brachiopods clades). Consequently, progenesis may be a significant evolutionary process for organisms, such as planktic foraminifera, that display a marked ecological separation between juveniles and adults not because the adult morphology has undergone substantial modification (the traditional 'escape from specialization' argument), but because it allows the progenetic descendant to become a permanent member of an ecological community that its ancestors simply passed through on their way to someplace else. Moreover, given the demonstrated ability of many progenetic faunas to colonize species-poor but resource-rich habitats (Gould, 1977), it is perhaps not surprizing that the planktic foraminiferal faunas remaining after major reductions of planktic foraminiferal diversity (such as the Cretaceous/Tertiary boundary and during the Paleogene-Neogene transition) were, on the whole, species that arose fairly rapidly, exhibited relatively simple globigerine test morphologies along with small test sizes and preferentially inhabited the surface waters (Cifelli, 1969; Lipps, 1970).

The case for a heterochronic interpretation of the observed patterns of size and shape variation in S. linaperta at Site 612 is based solely on the comparison between Middle Eocene and Late Eocene faunas. Questions concerning the identity of the environmental agent(s) responsible for this evolutionary change, and the rate at which this change took place are logically independent from the morphological identification of progenesis itself. However, it is known that the interval from the Middle through Late Eocene was a time of widespread oceanographic change including a permanent drop in bottom water temperature (Shackleton and Kennett, 1975; Douglas and Savin, 1978; Keigwin, 1980), global deepening of the CCD (Berger, 1972; Van Andel et al., 1975), lowering of sea level (Vail and Hardenbol, 1979; Haq et al., 1987; Keller et al., 1987), development of the psychrosphere (Benson, 1975), intensified bottom water circulation (Keller et al., 1985; Miller et al., 1985), fluctuations in the thermal structure of surface waters (Keller, 1983) and the incidence of multiple impacts of extraterrestrial objects (Keller et al., 1983; Keller et al., 1987; Hazel, in press). While most of these environmental changes occurred more or less continuously throughout the interval from the Middle Eocene through the Oligocene, it is noteworthy that multiple layers of impact ejecta are confined to those planktic foraminiferal biozones in which substantial shifts in relative abundance patterns as well as morphological changes are taking place in a number of planktic foraminiferal lineages (Keller et al., 1987). Indeed, Thein (1987) and Glass (1988) have pointed out that, owing to the co-occurrence of exceptionally large tektites, dense concentrations of microtektites, and shocked minerals in a $2 \mathrm{~cm}$ thick layer of sediment at Site 612 , this site was probably located in the proximate vicinity of such an impact. Viewed in this light, the obvious morphological similarities between $S$. linaperta populations at Sites 612 and 94 may be indicative of the operation of a single causal process on proximate and distally located populations that, given the timing of the size change at Site 94 , might have occurred 
during the late $G t$. semiinvoluta or early $T$. cerroazulensis biochronozones. Viewed in this light, the general character of test size decrease across the Middle to Late Eocene interval for $S$. linaperta at Site 612 appears to closely correspond to patterns of morphological variation exhibited by some Cretaceous/Tertiary planktic foraminiferal survivors (Keller, 1988). However, despite the speculative nature of such hypotheses, the research questions they engender are of fundamental importance to the understanding of planktic foraminiferal evolutionary patterns and can only be addressed through the explicit and quantitative study of phenotypic variation in each stage of the planktic foraminiferal life cycle.

\section{Summary}

Both progenesis and extinction have traditionally been dismissed as lacking evolutionary significance with the former described as an 'agent of degeneration' (De Beer, 1958) and the latter designated as the 'negative side of evolution' (Eldredge, 1985). Recent reassessments, however, have lead to the realization that shifts in developmental timing may be major sources of evolutionary innovation and that extinction can be a significant motive force in evolution through the reattainment of ecological opportunity by surviving taxa (Gould, 1977, 1985; Maynard Smith, 1984). What this investigation provides in terms of documenting evolutionary processes in the fossil record is an example of the potentially creative role of environmental perturbations to promote intraspecific divergence, should the perturbation trigger a population-level developmental response.

Quantitative comparisons of test size and shape changes between Middle Eocene ( $M$. lehneri zone) and Late Eocene ( $T$. cerroazulensis zone) populations of $S$. linaperta at Site 612 have shown that the small globigerine morphotype that came to dominate the Late Eocene planktic foraminiferal fauna at Site 612 was morphologically unique and that these morphological changes were also accompanied by equally unique and temporally persistent changes in this population's relative abundance and depth habitat. Quantitative morphological analyses indicate that the most viable interpretation of these data is that the observed test size decrease along with associated changes in overall test shape were brought about as a consequence of the developmentally accelerated attainment of sexual maturity by these Late Eocene populations, relative to their Middle Eocene ancestors whose primary result was to engender a change in this population's environmental (depth) habitat with the observed morphological changes being, most likely, secondary consequences of the shift in developmental pattern. Processes such as this, involving a change in developmental timing to accomplish a change of habitat, have been successfully employed by a wide variety of organisms and may represent a common evolutionary theme among taxa (such as planktic foraminifera) whose habitat and ecology undergo substantial alteration during the course of ontogeny.

Although it is not possible to know the age or the rate at which the morphological change in the Site $612 \mathrm{~S}$. linaperta populations occurred, data from coeval faunas indicate that similar types of morphological variations may have been occurring in conspecific populations as far away as the Gulf of Mexico. Provided that patterns of morphological variation in the more temporally complete Gulf of Mexico sections are similar to those that are missing at Site 612, we may suspect that the major portion of the phenotypic shift in these Late Eocene populations occurred sometime during the $G t$. semiinvoluta Biozone. In view of the fact that this interval is also characterized by the incidence of impact events, along with clear evidence for a Late Eocene impact even occurring in the immediate vicinity of Site 612 that included the Gulf of Mexico in its zone of direct physical disturbance (Keller et al., 1987), we believe there is sufficient reason to suspect that a catastrophic environmental perturbation may have resulted in increasing the intraspecific variability of this species of planktic 
foraminifera by altering established patterns of phenotypic development. If such alterations in developmental timing constitute typical modes of response by planktic foraminifera to intervals of major environmental change (either sudden or prolonged), the comparative study of phenotypic development in fossil foraminifera may provide useful insight into some of the fundamental problems of planktic foraminiferal evolution.

\section{Acknowledgements}

We thank K.C. Lohmann, D.L. Dettman and P. Koch and E. Barrera for performing stable isotopic analyses on samples from Sites 612, 94 and 363 , W. Stein for use of his digitizing tablet during an early phase of quantitative morphologic data collection, and K.-Y. Wei as well as two anonymous reviewers for critically reading the manuscript and offering many helpful suggestions. Morphometric data were, in part, collected with the Biosonics (OPRS) Optical Pattern Recognition System. This study was funded by NSF grant BSR-8708563 to N. MacLeod and J.A. Kitchell.

\section{References}

Alberch, P., Gould, S.J., Oster, G.F. and Wake, D.B., 1979. Size and shape in ontogeny and phylogeny. Paleobiology, 5: 296-317.

Alberch, P., 1982. Developmental constraints in evolutionary processes. In: J.T. Bonner (Editor), Evolution and Development. Springer-Verlag, pp. 313-332.

Anderson, T.W., 1963. Asymptotic theory for principal component analysis. Ann. Math. Stat., 34: 122-148.

Bé, A.W.H., 1980. Gametogenic calcification in a spinose planktonic foraminifera, Globigerinoides sacculifer (Brady). Mar. Micropaleontol., 5: 283-310.

Bé, A.W.H., 1982. Biology of planktonic foraminifera. In: T.W. Broadhead (Editor), Foraminifera: Notes for a Short Course. Studies in Geology, Univ. Tennessee, pp. 51-92.

Benson, R.H., 1975. The origin of the psychrosphere as recorded in changes of deep-sea ostracode assemblages. Lethaia, 8: 69-83.

Berger, W.H., 1972. Deep-sea carbonates: dissolution facies and age-depth constancy. Nature, 236: 392-395.

Blackstone, N., 1987a. Allometry and relative growth: pattern and process in evolutionary studies. Syst. Zool., 36: 76-78.

Blackstone, N., 1987b. Size and time. Syst. Zool., 36: 211215.
Blow, W.H., 1979. The Cainozoic Globigerinida. E.J. Brill, Leiden, $1413 \mathrm{pp}$.

Bookstein, F.L., 1986. Size and shape spaces for landmark data in two dimensions. Stat. Sci., 1: 181-242.

Bookstein, F.L., 1989. Principal warps: thin-plate splines and the decomposition of deformations. IEEE Trans. PAMI, 11:567-585.

Boltovskoy, E. and Wright, R., 1976. Recent Foraminifera. Dr. W. Junk, The Hague, $515 \mathrm{pp}$.

Bonner, J.T., 1982. Evolution and Development. Springer-Verlag, Heidelberg, $430 \mathrm{pp}$.

Brummer, G.A., Hemleben, C. and Spindler, M., 1987. Ontogeny of extant spinose planktonic foraminifera (Globigerinidae): a concept exemplified by Globigerinoides sacculifer (Brady) and G. ruber (D'Orbigny). Mar. Micropaleontol., 12: 357-381.

Burnaby, T.P., 1966. Growth-invariant discriminant functions and generalized distances. Biometrics, 22: 96-110.

Buss, L.W., 1987. The Evolution of Individuality. Princeton Univ. Press, 197 pp.

Cifelli, R.S., 1969. Radiation of Cenozoic planktonic foraminifera. Syst. Zool., 18: 154-168.

Craig, H., 1957. Isotopic standards for carbon, oxygen and correction factors for mass spectrographic analysis of carbon dioxide. Geochim. Cosmochim. Acta, 12:133140.

De Beer, G.R., 1958. Embryos and Ancestors. Clarendon Press, Oxford, $108 \mathrm{pp}$.

Douglas, R.G. and Savin, S.M., 1973. Oxygen and carbon isotopic analysis of Cretaceous and Tertiary foraminifera from the central north Pacific. Initial Reports of the Deep Sea Drilling Project, 17. U.S. Government Printing Office, Washington, D.C., pp. 591-605.

Eldredge, N., 1985. Unfinished Synthesis. Biological Hierarchies and Modern Evolutionary Thought. Oxford Univ. Press, $216 \mathrm{pp}$.

Glass, B.P., Meunow, D.W. and Aggrey, K.E., 1986. Further evidence for the impact origin of tektites. Meteoritics, 21: 369 .

Gould, S.J., 1969. An evolutionary microscosm: Pleistocene and Recent history of the land snail $P$. (poecilozonites) in Bermuda. Bull. Mus. Comp. Zool., 138: 407-532.

Gould, S.J., 1977. Ontongeny and Phylogeny. Harvard Univ. Press, 439 pp.

Gould, S.J., 1985. The paradox of the first tier: an agenda for paleobiology. Paleobiology, 11:2-12.

Gould, S.J., 1989. The uses of heterochrony. In: M.L. McKinney (Editor), Heterochrony in Evolution, Plenum, New York, pp. 1-13.

Hallam, A., 1965. Environmental causes of stunting in living and fossil marine benthonic invertebrates. $\mathrm{Pa}$ laeontology, 8: 132-155.

Haq, B.U., Hardenbol, J. and Vail, P.R., 1987. Chronology of fluctuating sea levels since the Triassic. Science, 235: 1156-1166.

Hazel, J.E., (1989). Chronostratigraphy of Upper Eocene microspherules. Palaios, 4: 318-329. 
Hemleben, Ch., Spindler, M. and Anderson, O.R., 1989. Modern Planktonic Foraminifera. Springer-Verlag, Heidelberg, 363 pp.

Hemleben, C. and Spindler, M., 1983. Recent advances in research on living planktonic foraminifera. Utrecht Micropaleontol. Bull., 30: 141-170.

Jolicouer, P., 1963. The multivariate generalization of the allometry equation. Biometrics, 19: 497-499.

Keigwin, L.D., 1980. Paleoceanographic change in the Pacific at the Eocene-Oligocene boundary. Nature, 287: 722-725.

Keller, G., 1983. Paleoclimatic analyses of Middle Eocene through Oligocene planktic foraminiferal faunas. $\mathrm{Pa}$ laeogeogr., Palaeoclimatol., Palaeoecol., 43: 73-94.

Keller, G., 1986. Stepwise mass extinctions and impact events: Late Eocene to Early Oligocene. Mar. Micropaleontol., 10: 267-293.

Keller, G., 1988. Extinction, survivorship and evolution across the Cretaceous/Tertiary boundary at El Kef, Tunisia. Mar. Micropaleontol., 13: 239-263.

Keller, G., D'Hondt, S.L. and Vallier, T.L., 1983. Multiple microtektite horizons in Upper Eocene marine sediments: no evidence for mass extinctions. Science, 221: 150-152.

Keller, G., Chi, W.R., D'Hondt, S., Dorsey, R., Herbert, T. and Johnson, M., 1985. Global sedimentation and distribution of deep-sea hiatuses: Late Eocene-Oligocene. Abstr. Programs, Geol. Soc. Am., p. 625.

Keller, G., D’Hondt, S.L., Orth, C.J., Gilmore, J.S., Oliver, P.Q., Shoemaker, E.M. and Molina, E., 1987. Late Eocene impact microspherules: stratigraphy, age and geochemistry. Meteoritics, 22: 25-60.

Keller, G. and MacLeod, N., (in press). Faunal turnover and depth stratification: their relationship to climate and productivity events in the Eocene to Miocene pelagic realm. In: K. Ishizaki (Editor), Takayanagi Testimonial Volume, Tohoku Univ.

Kurtén, B., 1959. Rates of evolution in fossil mammals. Cold Spring Harbor Symp. Quant. Biol., 34: 205-215.

Lipps, J., 1970. Plankton evolution. Evolution, 24: 1-22.

Lister, A.M., 1989. Rapid dwarfing of Red Deer on Jersey in the last intergracial. Nature, 342: 539-542.

Lovtrup, S. and von Sydow, B., 1974. D'Arcy Thompson's theorems and the shape of the molluscan shell. Bull. Math. Biol., 36: 567-575.

MacLeod, N., (in press). Effect of Late Eocene impacts on planktic foraminifera. In: V.L. Sharpton and P. Ward (Editors), Proceedings of the Conference on Global Catastrophes in Earth History: An Interdisciplinary Conference on Impacts, Volcanism, and Mass Mortality. Geol. Soc. Am. Spec. Publ.

MacLeod, N. and Kitchell, J.A., (in press). Morphometrics and evolutionary inference: a case study involving ontogenetic and developmental aspects of evolution. In: F.J. Rohlf and F.L. Bookstein (Editors), Proceedings of the NSF-University of Michigan Workshop on Morphometrics and Systematics, Univ. Michigan, Ann Arbor.

Maglio, V.J., 1973. Origin and evolution of the Elephantidae. Trans. Am. Philos. Soc. N.S., 63: 1-49.

Marshall, L.G., 1974. Late Pleistocene mammals from the
"Keilor Cranium Site," Southern Victoria, Australia. Mem. Nat. Mus. Victoria, 35: 63-86.

Marshall, L.G. and Corruccini, R.S., 1978. Variability, evolutionary rates, and allometry in dwarfing lineages. Paleobiology, 4: 101-119.

Maynard Smith, J., 1984. Palaeontology at the high table. Nature, 309: 401-402.

McNamara, K.J., 1986. A guide to the nomenclature of heterochrony. J. Paleontol., 60:4-13.

McNamara, K.J., 1989. The abundance of heterochrony in the fossil record. In: M.L. McKinney (Editor), Heterochrony in Evolution. Plenum, New York, pp. 289318.

Miller, K.G., Mountain, G.S. and Tucholke, B.E., 1985. Oligocene glacio-eustasy and erosion on the margins of the North Atlantic. Geology, 13:1-13.

Miller, K.G., Fairbanks, R.T. and Mountain, G.S., 1987. Tertiary oxygen isotope synthesis, sea level history and continental margin erosion. Paleoceanography, 2: 119.

Prothero, D.R. and Sereno, P.C., 1982. Allometry and paleoecology of medial Miocene dwarf rhinoceroses from the Texas Gulf Coastal Plain. Paleobiology, 8: 16-30.

Raff, R.A. and Kaufman, T.C., 1983. Embryos, Genes, and Evolution: The Developmental-Genetic Basis of Evolutionary Change. Macmillan, London, 549 pp.

Reyment, R.A., 1969. A multivariate growth problem. Biometrics, 15: 1-8.

Rohlf, F.J. and Bookstein, F.L., 1987. A comment on shearing as a method for 'size correction'. Syst. Zool., 36: 356-367.

Shackleton, N.J. and Kennett, J.P., 1975. Paleotemperature history of the Cenozoic and the initiation of Antarctic glaciation: oxygen and carbon isotope analyses in DSDP Sites 277, 279 and 281. Initial Reports of the Deep Sea Drilling Project, 29. U.S. Government Printing Office, Washington, D.C., pp. 743-755.

Snyder, J. and Bretsky, P.W., 1971. Life habits of diminutive bivalve molluscs in the Maquoketa Formation (Upper Ordovician). Am. J. Sci., 271: 227-251.

Steineck, P.L. and Fleisher, R.L., 1978. Towards the classical evolutionary reclassification of Cenozoic Globigerinacea (Foraminiferida). J. Paleontol., 52: 618-635.

Tasch, P., 1953. Causes and paleoecological significance of dwarfed fossil marine invertebrates. J. Paleontol., 27: 356-444.

Thein, J., 1987. A tektite layer in Upper Eocene sediments of the New Jersey continental slope (Site 612, Leg 95). Initial Reports of the Deep Sea Drilling Project, 95. U.S. Government Printing Office, Washington, D.C., pp. 565-579.

Vail, P.R. and Hardenbol, J., 1979. Sea level changes during the Tertiary. Oceanus, 22: 71-80.

Van Andel, T.H., Heath, G.R. and Moore, T.C. Jr., 1975. Cenozoic history and paleoceanography of the central equatorial Pacific Ocean. Geol. Soc. Am. Mem., 143: $1-134$.

Wassersug, R.J., Yang, H., Sepkoski, J.J. Jr. and Raup, D.M., 1979. The evolution of body size on islands: a computer simulation. Am. Nat., 114: 287-295. 